\title{
L'uso dell'enbucrilato nell'allestimento di fistole artero venose distali nei pazienti emodializzati anziani
}

\author{
G. Bacchini, G. Pontoriero, F. Fabrizi, P. Marai \\ Divisione di Nefrologia e Servizio di Dialisi Ospedale di Lecco
}

ra i fattori prognostici del paziente in trattamento emodialitico, risulta sempre più essenziale l'importanza dell'accesso vascolare. Idealmente l'utilizzo dell'accesso vascolare deve garantire un incannulamento facile e ripetibile, oltre a consentire un flusso ematico adeguato ad una dialisi efficiente, non favorire fenomeni di ricircolo, garantire una lunga durata e non costituire una eccessiva limitazione allo svolgimento di una normale attività quotidiana. L'allestimento di fistole artero venose distali costruite partendo dai vasi propri del paziente è la forma preferita e chirurgicamente più semplice per l'accesso vascolare. Originariamente fu descritta una tecnica di microchirurgia vascolare che prevedeva l'anastomosi latero-laterale tra la vena cefalica e l'arteria radiale del- l'avambraccio in prossimità del polso, al di sotto del legamento trasverso del carpo (1). Questa classica FAV come descritta da Cimino, è stata progressivamente abbandonata, utilizzando preferibilmente anastomosi termino-terminali (T-T) o latero-terminali (L-T) (Fig. 1).

A partire dal 1970 il primo nostro approccio all'accesso vascolare è rappresentato dalla fistola termino terminale al
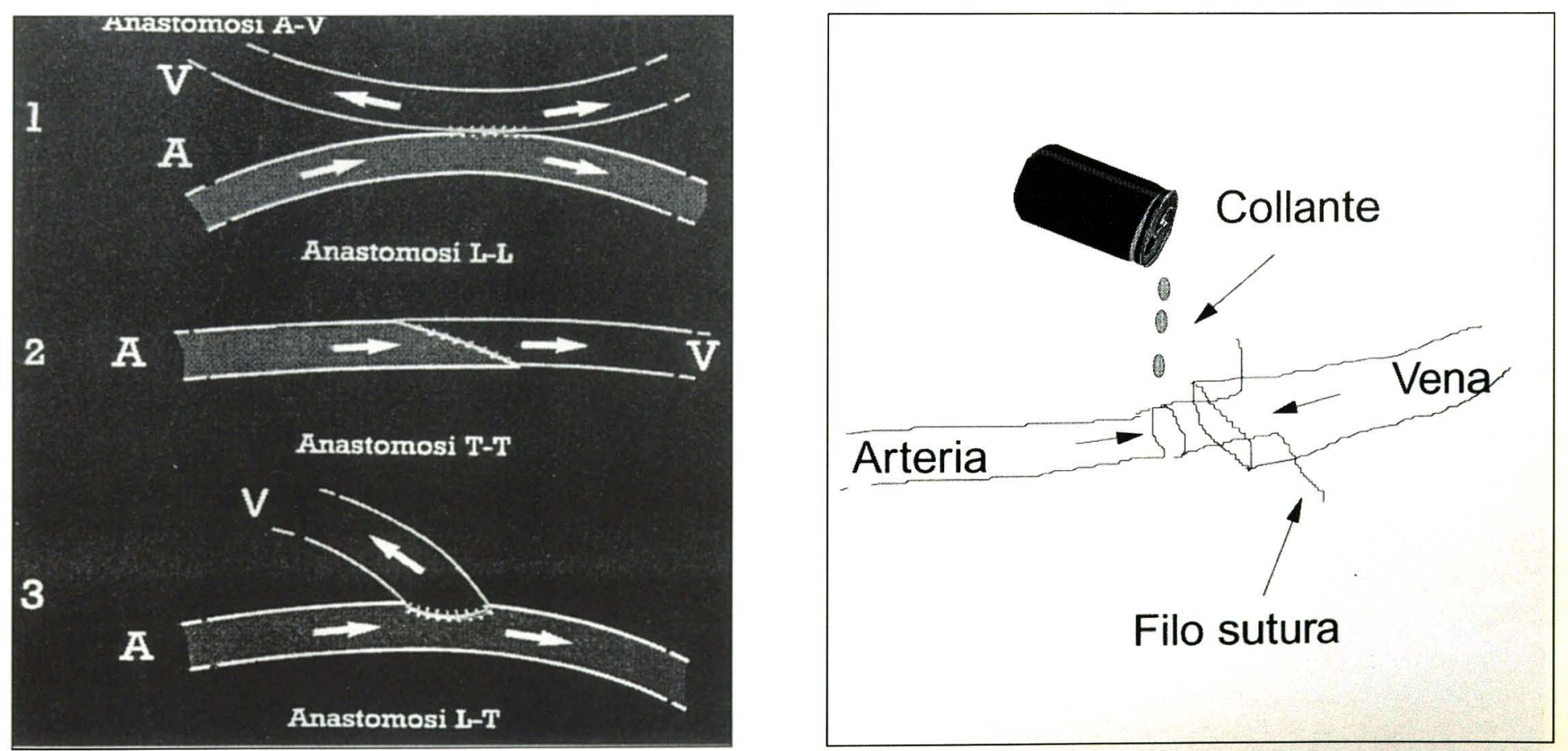

Fig. 1 
polso effettuata con collante tissutale (enbucrilato). Tale tipo di collante consente di ridurre sia i tempi che la difficoltà nell'esecuzione dell'intervento, liberando quindi l'equipe dalla dipendenza da uno o due chirurghi esperti. In figura due abbiamo cercato di rappresentare la tecnica chirurgica di utilizzo di questo collante (Fig. 2).

Allo scopo di poter valutare la validità e l'efficacia dell'utilizzo dell'enbucrilato nel confezionamento delle fistole artero venose termino terminali distali abbiamo valutato la sopravvivenza di tale tipo di accesso vascolare, analizzando i dati a partire dal 1991.

A partire da tale data abbiamo effettuato 363 interventi così suddivisi:

\begin{tabular}{lcc} 
& $\begin{array}{c}\text { Avambraccio } \\
\text { destro }\end{array}$ & $\begin{array}{c}\text { Avambraccio } \\
\text { sinistro }\end{array}$ \\
\hline Primi & 63 & 119 \\
interventi & 48 & 133 \\
Revisioni & $64 \pm 11.9$ & $63.4 \pm 13.9$ \\
Età media & $64 \pm$ \\
\hline
\end{tabular}

In totale sono stati studiati 162 pazienti; la curva di sopravvivenza della metodica è stata calcolata con il test di KaplanMeier.

\begin{tabular}{cccc}
\hline $\begin{array}{c}\text { Durata } \\
\text { mesi } \\
\%\end{array}$ & $\begin{array}{c}\text { Soprav- } \\
\text { vivenza } \\
\text { inf. }\end{array}$ & $\begin{array}{c}\text { 95\% C.I. } \\
\text { Valore } \\
\text { super. }\end{array}$ & $\begin{array}{c}\text { 95\% C.I. } \\
\text { Valore }\end{array}$ \\
\hline 1 & 90.5 & 83.1 & 94.8 \\
2 & 86.6 & 77.3 & 91.1 \\
3 & 82.6 & 73.7 & 88.6 \\
4 & 78.3 & 69 & 85.2 \\
5 & 77.1 & 67.6 & 84.2 \\
6 & 75.9 & 66.2 & 83.2 \\
7 & 74.6 & 64.7 & 82.2 \\
8 & 73.2 & 62.9 & 81 \\
12 & 71.4 & 60.8 & 79.6 \\
16 & 59.5 & 46.7 & 70.1 \\
21 & 51 & 36.9 & 63.5 \\
24 & 37.7 & 21.7 & 53.6 \\
\hline
\end{tabular}

Abbiamo ottenuto i seguenti risultati:

Alla luce di questi risultati appare evidente come a 21 mesi il $50 \%$ delle fistole effettuate con il collante tissutale siano ancora funzionanti.

Considerando quindi i vantaggi di tipo sia tecnico, che di risparmio di tempo, possiamo concludere come l'uso dell'enbucrilato nella confezione delle fistole artero venose termino terminali sia da consigliare, come primo approccio nella confezione dell'accesso vascolare dei pazienti in trattamento emodialitico cronico. 